\title{
Where do Indian Institutes fall short with respect to World Class Institutes ? "Gap Analysis"
}

\author{
B. M.Naik \\ Board Member, Government College of Engineering Aurangabad 431005 \\ Founder Principal, Shri Guru GobindSingji College of Engineering Nanded 431606 \\ SPFU member, State Steering Committee member, TEQIP, Maharashtra State
}

\begin{abstract}
Indian institutes do not stand high in the world list of educational institutions. Thousands of students every year go abroad for higher education. Foreign universities have started coming into India. Universities in India are being blamed for producing unemployable graduates. UGC (University Grants Commission) in India appears to have failed in its mandated mission. A committee appointed by MHRD (Ministry of Human Resource and Development), Government of India, under the chairmanship of Mr. Hari Gautamrecommended that UGC be abolished. Higher and technical education is behind the needs of themodern times, adversely affecting economic and social growth in India. Both the President and Prime Minister of India have been publicly expressing concern on this account for many years. Yet no improvement is noticed. Some Chinese universities on the other hand have shot up from very low ranking to 35 in the world. Are the words of President and Prime Minister falling on deaf ears? Are they merely speaking like parrots from year to year? Indian institutes are insensitive and woefully unsuited to global demands and are too far behind the world. Do we need to dream big, think great and show commitment to improve? It is said that those who dream big perform better; dreams give energy to minds, mobilize resources and make people competitive and ambitious.
\end{abstract}

\section{B. M.Naik}

Board Member, Government College of Engineering Aurangabad 431005

Founder Principal, Shri Guru GobindSingii College of Engineering Nanded 431606

SPFU member, State Steering Committee member, TEQIP, Maharashtra State
The presence of world class institutions is a differentiating factor between the developed and the developing world. They produce globally competent leaders with high intellectual capability so badly needed to raise a nation to greater heights. They produce intellectual capital so essential for the welfare of people. Regions, nations and cities, even if endowed with abundant natural resources like minerals, land, water,etc., are not prosperous if they do not have world class higher education institutes. Knowledge institutions are like "Light Houses" to society. They are reference points providing guidance and giving direction to people and industry in stormy changes. This is an age of technology, in which scientific and technological capabilities matter most. Making the institutions world class is not an option but a compulsion. It is now not only a matter of spending more money, appointing more men, or providing infrastructure. It is more a matter of adopting appropriate visions and missions and selecting strategies. Indian education system is still traditionbound. Outdated systems like affiliated colleges, lack of autonomy,absence of research and Intellectual Property Rights (IPR), have crippled the education. Investments being made by government are subsidizing only the inefficiencies. This is because they lack a strategic outlook.

Indian professors abroad have done wonders. Why cannot they perform wonders in India? Is it because they have to work here in India with poor systems and poor governance? This paper recommends adoption of autonomy, research approach, creation of research parks, commercial exploitation of findings of 
research, patenting, enabling professors to be globally competitive, increasing mobility of professors, etc. This article presents in brief, the gap analysis in respect of visions and missions, policies and practice, organization structures, systems and procedures in India and their counterpart institutions in developed countries. Transformation of higher and technical education to world class level is critical to nurturing able leaders in various professions and vocations, and in critical to turn people's well-being.

\section{Introduction}

The vision of the government for education in India is poor, and so India, in spite of intellectual human resources and abundant natural resources, remains poor. It is said India is a rich country but inhabited by poor people. Economic poverty is so rampant that the $30 \%$ people living below poverty line, is a mirror image of poverty in education. India can perform much better if global winds of change are cared for, and if India adopts world proven policies and practices

Why thousands of students every year go abroad? Have we failed as a society to provide adequate opportunities to our youth to be educated in world class manner? Have we failed in creating a vibrant educational ecosystem that supports cutting edge research? How are their institutes different from Indian? What do they teach which we do not? Where do we go wrong? The teaching profession in India is in a grim state of affairs, whereasit is considered prestigious in foreign countries. Teachers encourage too much of rote learning in Indian institutions. Teachers in institutions abroad encourage more of innovation and creativity. Almost all teachers abroad hold doctorate degree, where as in India very few hold doctorate degrees. Why is the coaching industry in Indiabooming? Nalanda and Taxshila were the first universities of the world, where scholars used to come from abroad. Why has a shift in culture taken place, with our scholar students going abroad? Is it due to inadequate value attached to discovery of new knowledge and new theories? It is essential at this juncture of time to introspect and learn from the world experience in science and engineering education. The future of youths depends on knowledge, rather than resources. Status of India in the world, in leadership, income level, and well-being of people depends on its scientific and technological capability. To cope with challenges India will have to enlarge the scope of institutions to cover research, innovation, creativity, generation of theories, technology creation, patent and IPR, creation of new technology based firms, etc. What value do we attach to the above in budgeting? How can we bring back the past glory of Nalanda?Students studying today in universities are tomorrow's leaders, in politics, industry, academics etc. They sit in parliament, boardrooms, write books, become creative thinkers, and drive the society to progress. For India to win in the world economy they have to be competitive by world standards. To be able to have world class leaders tomorrow we have to have world class professors and world class institutes today. They have to learn not only known knowledge but learn to discover the unknown. These are critical to the success. IITs were set up under foreign collaboration. Their visions missions, policies and practices are molded along foreign lines. Hence they could shine. This paper observes that rest of the Indian higher education is far too behind. India will have to capitalize on emerging technologies to fulfill people's needs. Institutions will have to have wellsprings of new knowledge like in developed countries and not remain mere reflection centers. The gap analysis presented here makes an attempt to find answers to the questions raised above.

Knowledge institutions are extremely important in today's Knowledge Society. Knowledge institutions in developed countries are giving "Technology Push" matching with "Market Pull" to various vocations and professions. They are like heart to our body. They pump fresh blood, new knowledge to various organs of the society. This is a competitive world in which nations are competing on innovation, technological, organizational and financial innovation. World class institutes in knowledge society of today are now a prerequisite for an economy to prosper, this is the beauty in knowledge driven society of today that knowledge is more important than resources. Governments of various countries have realized that universities provide leaders to economies and that the kind of leaders they provide matters. If they provide world class leaders to manage its national and international affairs, the economy and peoples standard of living tends to become better; otherwise it remains mediocre, leading people to low standard below poverty line. High quality education is now extremely critical to the well-being of people. Educating students in a traditional way is no longer effective. Modern ways to educate in innovation, research creativity and discovery have become essential. India needs to produce graduates of global standard, and this demands globally competent 
institutes, with good systems for governance. It is the academic leadership at state, centre and institute levels which urgently need to be boosted. India faces challenges which can be addressed mostly by high quality education.

It is the educational institutions which are furthering human civilization to greater heights. It is the academicians who provide new knowledge, new theories new technology and competent manpower to industry, leaders to government and leaders to the world economy. This in turn creates wealth and comforts. Industry, society and government in return ought to provide funds to academics to make it grow. India, and for that matter any nation, can be richer only by use of advanced knowledge. There is no other way. The kind of leaders our institutes produce matter the most.

This is a time characterized by change. The world, under the forces of globalization, is changing fast. Institutions need to also change. Only those who change to innovate and again innovate tend to educate their youths along correct lines. Students now demand world class education. Institutions in India will have to be competitive by being nothing less than world class so as to remain in service. Otherwise, foreign universities will come here and capture major share of education market, and our students like in the past will keep going abroad.

People in India are as intelligent and hard working as elsewhere in the world. However, today their efforts do not bring fruits as much as their counterparts. We work six days a week as against five days in foreign countries. Yet per capita income is around only 1000 dollars whereas that of USA is 30,000 dollars. They work less and earn more. $30 \%$ people in India, live below the poverty line. It is mainly because of the lack of new visions of new world. It is due to lack of dedicated effort to realize the vision. We lack vision of research based education, relevant to the current needs.

The systems employed in India in education and all other walks of life are less efficient than those in developed countries. Indians, when they migrate abroad, are found to contribute far more. It is the systems efficiency which enables people to contribute more. We are spending resources and efforts on education but because of outdated systems output is less.Indian students study so much with less relevance. Foreign students study much less but with high relevance. This makes them more competitive. Our visions and missions, policies and practices, systems and procedures need examination in the light of world proven policies and practices. They need substantial improvement.Hence, the importance of gap analysis.

\section{Identification of Gaps, and their Analysis}

The paper presents only critical gaps which demand immediate attention. They are presented with a constructive criticism.

Where do the Indian institutes differ from their counterparts abroad? The universities in foreign are innovative in character; ours are conservative. They teach sunrise technology; we teach sunset. They produce leaders; we produce followers, imitators, copy cats. They are engines of growth; we remain bogies. They are not afraid of change; we are. They embrace change; we resist change. They practice creative destruction, they destroy old outdated systems and procedures; we cling to past. Their institutions are research based; ours are teaching oriented. They teach tomorrow's knowledge today; and we teach yesterday's knowledge today. They produce entrepreneurs and job generators; we produce employees, job seekers. Their universities produce hundreds of patents and new technology based companies. Framework of Indian universities is far too weak. Foreign universities create a mindset of students in favor of innovation; we create their mindset in favor of examination, memorization. Their labs have generated and given birth to new theories and new technologies and are not merely testing what has been discovered long back. In our institutions, what is wanted is not taught and what is taught is not wanted. The institutes abroad are ahead of time, are we behind?

- Innovative Infrastructure:

Universities abroad have on campus, technology relay centers, entrepreneurship centers, technology incubators, business incubators, research parks, venture capital foundations, patent and intellectual property centers, corporate education canters, technology transfer offices as well as knowledge transfer centers for outreach. They have beenexisting from many years, whereas we do not have them even today in India. It is on account of these shortcomings that their nations and people have prospered. These are the new dimensions to be added to our institutions. 
They are profit centers and have added to the wealth of universities and the nations abroad. These centers have given a character of innovation to their universities and made education relevant to the needs of the society. They generate new technology in college laboratories and so they are constantly selling and we buying them.

Quality and relevance of education in developed countries is reported to have improved because of the presence of such centers of excellence in the campus. Enterprising culture is imbibed in students while they are agile. This leads to spinoffs of new technology based companies, spinoffs of brand new technologies, continuous inputs of new technology in industries to make and maintain them globally competitive. Around 40 companies are born every year in MIT, and this figure over a period of years is of the order of 3000.Stanford University has given birth to companies like Yahoo, Google, and Cisco. This is true of almost all research universities. Universities have become the maternity homes, where good baby care is given and companies are born without any congenital defects. This is found to be a good help in building entrepreneurs. Companies born on university research parks are found to be more prospective at national and global levels, than those companies born off the park. Our universities are lacking in all such ideas. Can we not adopt these strategies? Yes, if such infrastructure is developed then the flow of students and brain drain will be arrested. True that it is a long journey, but somewhere it must begin. Is it not that a thousand miles journey begins with a single step? The vector direction of our students learning should have to be made enterprising, innovative and in right direction considering global experience. Otherwise the efforts, time and money goes astray. Only class room teaching or lab working although necessary is not enough to upgrade the quality of education to world class level. Imagination and creativity of students grows only when they work in research parks, incubators etc. and manage industry.

- Creativity, discovery, innovativeness is the character of institutes abroad. Is it so in India?Do we create leaders or followers?

I was reading an article written by an American author in the journal, "Fortune". The American writer was addressing the question, "Can India ever compete with US in software business?" To answer the question he made an analysis of higher education in both countries, and recorded that Indian system is rote learning, that is to say mechanical, stereo type based on memorization and not creative thinking. Students are taught sunset knowledge. Institutions in India do not produce new knowledge, new theories. Students are not learning innovation and hence they do not know how to discover unknown. They are reflection centers teaching knowledge which comes to them from developed countries. It does not focus on creativity, discovery and innovation. He came to the conclusion that Indian institutions can produce at best followers in technology but not leaders. On the other hand, thrust of US universities is on producing leaders, discoverers, creators, who obtain patents and intellectual property. It is US which is pumping new technology the most in the world market. $85 \%$ Of IPR is held by Americans. He said student's education in universities and colleges is an enabler to competitiveness of software industry. A nation creating followers can never compete with a nation creating leaders, unless in future it improves. Universities in India need to incorporate creativity in syllabi and aim to produce leaders.

Another study from Duke University was examining if there is a threat from India to US competitiveness. It observed that today the quality of Indian engineering schools is by and large poor. The number of $\mathrm{M}$. Tech. and $\mathrm{PhDs}$ who are crucial to technological innovation are too few and so India is far too behind in innovation. It concludes by saying that India on account of poor higher education does not pose a challenge to US competitiveness in near future.

- Research is main focus abroad. In India it is lacking.

Research is given a back seat in higher education. Professors and students have limited access to research grants and lack budget for research. Institutes and universities have become largely teaching shops. Professors teach sunset knowledge coming from abroad. They have no research skills. They learn like parrots, that which was taught to them ten years before. Neither the teachers nor students are trained to learn to discover what is unknown. Unfortunately teaching and research have been segregated from each other. This leads to weakening of both. This is not the way to build a nation. They therefore remain followers. Research must become the core function of an institution.

- Industry Institute Interaction Model. 
What we observe differently in higher education institutes abroad is that $R \& D$ units of private companies are flocking round and parking on the periphery of universities in search of new knowledge. These R \& D units draw on the intellectual capital of the university. They use the expertise of professors, use research infrastructure in university and the innovative talent of young energetic students. The experts in private $R$ \& $D$ units with their rich experience are found to deliver lectures to students studying in university. There is an exchange of knowledge and innovative talent continuously between the companies and the university. The interaction between the university and companies enriches both. By doing this, they subsidize each other's cost of education and research. Students learn innovation skills besides known knowledge and technology. This system especially fires the power of imagination of students, and inspires them with creativity. Thus research is found to subsidize education and education to subsidize research. Do we have such a system in our universities? This I have personally observed in many universities like McMaster University in Canada, Karlsruhe University in Germany, Wisconsin university in USA and several others. This is widely prevalent in many foreign universities for many years. In India we often talk of need and importance of interaction between industry and institute, in conferences. Do we need to emulate such good policies and practices from abroad?

- Universities abroad have been upgraded as birth places (maternity homes), of new technology based firms. How many of our universities do this?

MIT Boston is giving birth to as many as 50 companies every year. Microsoft was born in Harvard. Yahoo, Google, Cisco companies were born in Stanford University. There are more than 3000 companies which owe their origin to MIT. Australian universities are giving birth to 40 companies every year on an average per university [1]. Chinese universities of late are also doing the same. Why Indian universities cannot do this? How many companies are born in Indian universities? They can do this. But they need to have this vision. Where do our institutes stand in comparison with their counterparts? In the recent past, IIT Mumbai has set up a technology incubator, business incubator and research park. It has started spinning off hi-tech enterprises. Employment and income generation depends on new technology based firms. It is these companies which provide new life and blood to industries and keep them technologically up to date. This gap needs to be filled up with priority. Indian Universities need to drive to adopt new visions, such as their counterparts in other countries, to install a mechanism for spinning off companies. It is reported that IISC Bangalore has recently made collaboration with MIT Boston in this respect.

- Institutes abroad display patents for sale in Industrial Exhibitions.

Do we do that? Patents are unknown to institutions in India. It is good to do research but it is essential to make commercial exploitation of the findings of research. This makes research financially more viable, and attracts more funds. Today, the economic returns obtained from research done in India are far too few. This has been our weakness, and so actual funding for research does not grow.

A few years back I happened to visit Hannover industrial exhibition. There was a pavilion meant for universities and colleges. It was most crowded by the visitors. Students were explaining the new researches, emerging technologies like, patents and IPR to visitors from industry. Universities had come from world over to display. Visitors wanted to know the technologies of tomorrow. In India how many institutions have obtained patents and participated in industrial exhibition? Students do research for $\mathrm{PhD}$, M.Tech. theseswhich remain in the library. They are published in journals and is being harvested by foreigners for obtaining patents. We do not exploit research done commercially. Even the traditional knowledge like that of haldi, turmeric, ayurvedic medicines, wheat,etc. isbeing converted into patents by USA. We need to build this patent culture in our education. If the young students learn this they will follow in their future career. If they do not learn they do not practice. Attempts by Technology Information Forecasting and Assessment Council [TIFAC], New Delhi a government of India body, are being made to popularize patents and IPR. It has yet to reach universities and colleges. We need to protect our research findings before publication by patenting and convert it in money. Research is a wealth generating mechanism provided it is converted in to patents, IPR. When shall we realize this? [2]

Institutions in India today are distinctly a technology follower. They do not lead; do not give birth to new technology. They are by and large inward 
looking, restricting to class rooms and not going beyond. They lack the world vision. They are not enabled to think and act in this direction; the situation needs correction.

We need to install patent IPR centers in each institute and display patents in exhibitions. Industry is keen on knowing emerging technology. Institutes should aim at that. Visions of our institutions need to be enlarged, to go beyond to what their counterparts elsewhere in the world are doing.

They have Built Visions for patent IPR culture. Have we?

How many of our universities and colleges have patent culture? MIT Boston every year obtains around 100 patents. The institute has a Technological Licensing Office with 200 people working in it. There is a trend of commercialization of new technology in almost every university. It is a source of income to the professors, students and the institute. Many universities in Germany and UK have patent departments. In fact, their performance is measured in terms of how many patents are obtained and the revenue earned. They have Technology Incubators, Business Incubators, research parks and Venture Capital Firms available in campus. Students develop skills of innovation and patenting in them. This is our serious weakness. This is one of the important reasons why Indian students go abroad. We need necessarily to learn from international experience abroad.

- Institutions abroad are in driver's seat. Indian institutions are followers like bogies of a train.

A friend of mine 25 years back went to USA. He studied MS, PhD and then started a company in Silicon Valley. He returned to India after a gap of 25 years, we received him on the airport at Mumbai. He was curious to know about the progress made by India. We were driving by car to Pune. He was happy to see the new high way, as good as in USA. When we came to Pune I was telling him now we have entered Pune. He was not able to see any signs of his time on roads. He would not believe that this is Pune. He said how Pune can change so much, beyond recognition. We came on Deccan Gymkhana, yet he was not ready to believe that this is Pune. Then we came on Laxmi road. He did not see a single bicycle, which at his time used to be the common vehicle crowding the roads. Then we came to the railway station. He did not see a single horse-driventanga. He refused to accept that it was Pune. Then we brought him to the college where he studied. Immediately he exclaimed, now I cannot refuse. He said whole city has changed but his college has not. He said in USA cities change because of institutions. In India, institutions are followers of change.

Institutions in India, instead of becoming an engine have become bogies. This he said is an unfortunate situation. Legitimately institutions should initiate changes in society. Institutions need to have the attitude to shape development. Only those cities are well developed where universities are having such visions.

Institutes abroad have innovative character. They produce far more captains and generals (M.Tech, $\mathrm{PhDs}$ ); we produce more soldiers (B.Es.). Teaching Assistantship and Research Assistantship in India are almost absent.

I have visited more than two dozen universities in Germany, China, UK, US. I found that they are in the pursuit of discovery, research and innovation. [3] Their center of gravity is on post-graduation and doctoral studies. They produce far more graduates of advanced degrees. They produce more captains and generals. We produce more soldiers. They produced around $7720 \mathrm{PhDs}$ in 2006, where as in India around only 5000 are registered for $\mathrm{PhD}$, many of them are in service as lecturers from little known colleges. There are no schemes like teaching assistantship and research assistantship in many universities, to attract the fresh scholars. This is a serious short coming of our education.

It is on account of advanced courses offered in the foreign institutes that the quality of undergraduate (UG) programs becomes superior. They teach sunrise knowledge and sunrise technology. According to the report of G. Bush Commission, named "Science, the Endless Frontier", research is the main function of a university and teaching is a byproduct. Teaching without research leads to irrelevance, and obsolescence. In India this is the status.

Many universities in India teach sunset technologies to students. Institutions are behind the time. According to McKinsey report published recently only $30 \%$ of the engineering graduates are employable. Government has now proposed, "Finishing schools" in IITs and NITs to educate halfbaked graduates coming out of universities. From 
NASSCOM to CII, everybody is crying hoarse about the quality of our technical manpower.

Policy makers need to be educated to make policies which enable institutes to become innovative like they are abroad. Policy makers should enable the professors to be innovative and produce more of M.Tech and $\mathrm{PhDs}$, that is to say captains and generals. This is a major point of difference between Indian institutes and their counterparts abroad.

- Size of institutions abroad is large and hence economical. In India it is pigmy and uneconomical.

National University of Singapore has 350 acres of land but it has 1,900 professors and 32,000 students. MIT Boston has about 500 acres of land and 40,000 students with 3,000 professors. Georgia Tech University has 20,000 students and 1000 professors. It offers 130 different courses. Karlsruhe University in Germany has 30,000 students and 2,000 professors. Our universities by and large are pigmy in size. They have big land of the order of 1,000 acres but students and professors are far too few. Pankaj Jalote [4] in one of his articles has advocated scaling up the strength of students in IITs from 4,000 to 10,000. Courses offered are stereotyped besides too low in number. Most of the universities 1(such as Pune and Mumbai Universities) in their campuses have too few students and faculty. Aurangabad University for example has 500 acres of land, has 1000 students and has only 100 faculty strength. The size of our institutes is uneconomical. They are over-capitalized in terms of land and buildings. Universities abroad open at 8 in the morning and remain open up to midnight. We open at 10 in the morning and close at $5 \mathrm{pm}$. There is a big difference in libraries. They are far too behind. Capacity utilization of installed facility in India is too small. Private colleges in engineering are like small "pan shops" withoutPost Graduate (PG) and $\mathrm{PhD}$ education. There are no well springs of knowledge in the institutions. They depend on borrowed knowledge. The scope of our institutions needs improvement. They need to see what is happening elsewhere in the world and do benchmarking.

They give high priority to education in national budget. What priority we give?

Professor's profession is very important, but the profession is not made attractive in India. Education is not accorded the priority it deserves in the national budget. It does not get budget as much as their counterparts in other countries.India spends around $3 \%$ only whereas developed countries spend around $10 \%$ of GDP on education. Budget allocation to R\&D in India is only $0.8 \%$ of GDP where as in China it is $1.5 \%$. Papers published and patents obtained in China are ten times larger. Less number of people are, therefore, educatedand that too poorly. This adversely affects the quality of leadership in all walks of life. Technological content in economy is far too low. It is to be realized that it is education which makes a man competitive. Without education man is less than an animal. It is like training a cook to prepare food. A trained cook uses less material yet prepares tasty food. Untrained man is unfit to live a worthy life. Nobel Laureate Dr Amartya Sen recommended increasing budget on education. The then finance minister Mr. Yeshwant Sinha asked him what should be the first priority in budget. He replied Education. Then he asked what should be the second priority? He again replied, Education. Then he asked, what should be the third priority? He replied again Education. Should the Government care for his advice?

- Policy makers in India are not galvanized with new ideas

Foreign universities galvanize their leaders from time to time with new ideas. Do we? Strategies employed in India are too far behind the world. The strategies have almost no strength to take the nation forward. Research subsidizes education and education subsidizes research. Research and education are complementary to each other.This world proven fundamental strategy is not adhered to in India. Strategies adopted in India are not strong enough in comparison to the world.

There is a story of two armies which were fighting a battle with each other. One army had a lion as its captain, but the soldiers were sheep. The second army had a sheep as its captain and lions as soldiers. The lion captain employees bold strategies. The other captain, a sheep designs strategies like a coward and loses even though his soldiers are lions, because the soldiers have to follow the strategies drawn by captain. It is the strategies which enable the army to win.

Situation of India is something like sheep as captain. We have a strong base of intellectuals, and academicians but strategies which are drawn by leaders in bureaucracy and leaders in politics are weak. Academic leadership, as a result, at national/ 
state/ institution levels is crippled. Students of today are tomorrow's leaders. To have good leaders tomorrow we have to have good institutions today. Shivaji had much smaller army than Aurangzeb but still he could win, because he employed better and bolder strategies like a lion.

There is a greater need to shed the mental weakness in academicians. They need to be enabled to grow at par with their counterparts abroad.

\section{- Brain power is nursed abroad. Is it wasted in India?}

Brain poweris said to be more powerful than anyother power, like money power, political power, electrical power etc. Demand for knowledgeable people in a globalized world is sky rocketing. SEZs (Special Economic Zones) and industrial development plans demand people with skills like research, innovation, entrepreneurship, patenting and IPR. Nations which understand the dynamics of the world market, and match it with institutions, will win. Others may work hard, spend resources but will lag behind in brain race. Those who take strategies in favor of nursing brain power are the ones to win.

We have to recognize the importance of and work with knowledge and IPR rather than muscle. Salaries of only a few in industry are sky rocketing. Many on the other hand are jobless. They have brains but under nourished. The dichotomy can be resolved only by upgrading the institutions.

Academic freedom is the legal right of students and professors abroad. In India professors are servants without any academic freedom. They have to teach what is given in university syllabus. They cannot teach based on personal research. Students have no choice than to learn what is handed over to them.

Institutions also do not have academic freedom. This is proved from IIM-A (Indian Institute of Ahmedabad) case. They have become puppets in the hands of Government. Independent free thinking and decision making is not allowed. Courses are not offered using a "Cafeteria"(i.e. providing a wide range of courses to choose from) are not run, although this approach is badly needed. Industries are varied in nature and so are their manpower needs. Courses ought to be unique. Standardized stereotyped courses are giving birth to mediocrity. Hence industry of coaching classes is booming,
Academicians are being exploited by governing boards. The students and public at large are also being exploited. Academicians, however, ought to work in only public interest. Sometimes the government, institute and industry are too selfish and damage the interest of public at large. Academicians, therefore, ought not to work to further in the foul interest of institute, industry or government. They must behave fully in a professional manner. For this they have to be autonomous by law although they receive salary from institute, and from government or industry. World experience tells us that nations grow best only when academicians can function in autonomous manner.

Academicians generate sunrise knowledge and educate people to use it. They essentially should not have to go too close to education barons, industry or to government. They should have academic freedom to be able to play their legitimate professional role including that of a critic. Academicians have to work in larger public interest, for maintaining a healthy national economy. They should not have to bend before education barons, industry or government. They should have the freedom to work in the pursuit of new knowledge.

Indian economy is a low income economy mainly because of lack of application of new knowledge. All institutions and professors should forth with be made autonomous. Parliament and State assembly should pass laws in national interest empowering professors for the cause of education.

Universities, institutions and private colleges have become the prisoners in the hands of government. Non educational principles and strategies of government are guiding the people in universities and colleges. In fact it should be the other way round. Higher education institutes have become slaves of whims and fancies of government. They change every five years when a new party comes to power.

The scheme of contract appointment of lecturers on fixed salary of Rs. 12,000 is introduced in Maharashtra state. UGC (University Grants Commissions) and AICTE (All India Council for Technical Education) have objected. It has no backing of any academic body but only of bureaucracy. Mediocre people are getting in. Although cheap, quality of education is deteriorated. Can the entry of professionals in teaching be protected? How can we produce globally competent leader engineers? 
Government is not best qualified to govern education. Government should make only legislation for which it is meant. Long range policies and practices in education in India need be made by professionals considering the trends in world.

- Institutions are governed in India by those who have low value for academics.

Privatization of education is good provided it is governed by those who have value for academics. In most of the cases it is the politicians who do not understand it, and sit on the governing board. Today, education barons have usurped the powers of academicians. Professors have become humble servants[5]. They have no freedom to think, nor freedom to act. They have no budget for research, while money earned in colleges is siphoned for political purposes. This is too damaging for the future of children and grandchildren. That is one of the main reasons why brain drain from India is rampant.

Education barons have brought unethical commercial trends into education. Government is a party to it. In the current situation, thinkers have no place in education. Nobler aims of education are thrown to winds. Bottoms $50 \%$ of population do not have access to higher education, because fees are high. Upper $50 \%$ population is mediocre but wealthy, and so gets access to higher education. India with such policies will stand to lose in brain race in long range[6]. The fabric of Indian culture is likely to be damaged. At a time when the level of education needed for productive employment is increasing, opportunity to go to college to bottom half population is decreasing. The common man is getting a feeling of betrayal, causing resentment which may lead to discontent, instability, andeven riots, which may be very costly. The present policies are an aid toNaxalite movement. Education institutes cannot and should not be run on commercial lines like General Motors. Public interest is being sacrificed by both government and industry. When shall we realize this?

There is no affiliating system abroad. In India it is rampant. It has killed the innovation capacity of students. Chancellors of universities should not be the Governors of the states. Chancellors should be academicians. Policies are at fault.
Inbreeding in higher education is taking place. University Acts are obsolete. Governor of a state who is not an academician but a politician is at helm of affairs, as the chancellor of a university. Chairman of UGC, Chairman of AICTE are academicians. How come chancellors of universities are politician? This is not so abroad.

The chancellor of universities is the appointing authority for vice chancellors. He does appointments mostly on political considerations. Most of the Vice Chancellors (VCs) are misfits. He inducts politics in universities. The situation perpetuates down below. This has resulted in politicization of higher education. Blame is wrongly passed on to professors. Policy makers and the chancellors are truly at fault. The situation demands immediate change. We need to adopt international visions to improve.

Unless the change is brought in Chancellor's post as suggested above, the affiliating system may not go away. There are no affiliated colleges in developed countries. Every college from its beginning is autonomous.

- There are more number of technical universities abroad; India has very few.

Almost half of universities in US are technical. Germany has more than 84 technical universities[7].Japan also has many technical universities. It is observed that those nations which have more technical universities have capitalized technology more effectively[8]. India has more multifaculty universities. In these universities, technical discipline does not get the attention it deserves. Hence, India lags behind the world. AICTE (All India Council for Technical Education) has recommended establishment of exclusive technical universities. However in most of the states there is only one technical university and many colleges are affiliated to it. This creates monopoly and bureaucracy. As a result the efforts and investment by colleges and students do not get fruits they deserve. Agriculture Universities which were set up in sixties developed new varieties of seeds, which have resulted in increased food production. Technical Universities should not be only examination bodies awarding degrees but should generate new technologies and improve industrial production [9]. Future of children is linked up with creation of technical universities. 


\section{Conclusion}

Good ideas are available not only in India but also abroad. We should not close our eyes and ears to them. We should not miss to benefit from them. Exchange of knowledge, faculty, scholars ,etc.are necessary. It is too costly not to interact with the counterparts elsewhere in the world. Mobility of professors to world best universities at any cost must be planned in a big way on priority. This is the only way to build good leaders and to take India on world map. [10]

We lack visions and not the resources. We lack interaction with our counterparts elsewhere in the world. We lack dedicated efforts. Institutions, universities need to show new visions of new world which inspire students to become leaders on global level. Institutions ought to shift their culture in favor of creativity, IPR and discovery. India's growth rate can be sustainable only if academic institutions adopt innovative character. Visions drive the national economies forward. [11]

In this time of knowledge society it is the intellectual capital that counts. People work with hands, but it is the brain behind which gives inspiration. Government should have to attach more value in national budget to create and use new knowledge.

The paper has identified only a few gaps, which are critical and need to be attended to. Without this higher education will not be up to the mark to fulfill the growing aspirations of people. Opportunities do not last longer. They do not wait. Achieving the declared dream of India to become a developed country by the year 2020 depends on how ably and urgently we initiate steps to make up the gaps.

We must not forget to recognize the importance of IPR. Creation of favorable environment for the same should be our top priority.

Rapid upgradation of higher education institutes and universities in the light of experiences in the world should urgently be taken up. There is nothing more urgent for India at this juncture of time than reviving higher education.

\section{References:}

[1].Fang Zaho, Academic Entrepreneurship, Case study of Australian universities, Published in International Journal of Entrepreneurship and innovation, pp 91-97, IP Publishing Ltd. Vol 5 number 2; 2nd May 2004.

[2]B. M. Naik, Needed - Innovation and Entrepreneurship in Higher Education Institutes, published in Indian Journal Of Technical Education, January- March 2004 Vol 27, number $1, \mathrm{pp} 27-32$.

[3] Green paper of European Union on Innovation and technological transfer Enterprise Unit DG, EUFO, 2295-2920 Luxemburg.

[4] Pankaj Jalote, An Opportunity To Scale Up the IITs, Economic Times, 26April 2007.

[5] B. M. Naik, Privatization of Technical Education, Identification of Risk factors, and their Management- making Education affordable, Journal on Engineering and Technology, imanager publications, Volume 1, No 2.

[6] James J.Duderstadt, "A university for twenty first century"; The University of Michigan Press.

[7] Derek Bok, "Universities in the Market Place, The Commercialization of Higher Education"; Princeton University Press Princeton New Jersey.

[8] Clark Kerr and Marion L Gade, Association of College Boards of Universities of America., "The Guardians, Boards of Trustees of American universities and Colleges, What They Do and How Well they Do It".

[9] William G Bowen and Derek Bok, Princeton University Press, "The Shape of The River, Long Term consequences Of Considering Race in College and University Admissions".

[10]B. M. Naik Book, " New Vistas in Technical Education", Vivek publication, Aurangabad.

[11]V.Raghunathan, "India Needs More quality PhDs", published in economic Times. 